\title{
Gene specific modifications unravel ethanol and acetaldehyde actions
}

\section{Yedy Israel ${ }^{1,2 *}$, Mario Rivera-Meza ${ }^{1}$, Eduardo Karahanian ${ }^{3}$, María E. Quintanilla ${ }^{1}$, Lutske Tampier $^{1}$, Paola Morales ${ }^{1}$ and Mario Herrera-Marschitz ${ }^{1}$}

${ }^{1}$ Faculty of Medicine, Molecular and Clinical Pharmacology Program, University of Chile, Santiago, Chile

${ }^{2}$ Department of Pharmacological and Toxicological Chemistry, University of Chile, Santiago, Chile

${ }^{3}$ Faculty of Medicine, Center for Biomedical Research, Diego Portales University, Santiago, Chile

Edited by:

Merce Correa, University Jaume I,

Spain

Reviewed by:

Merce Correa, University Jaume I,

Spain

Etienne Quertemont, University of

Liege, Belgium

\section{*Correspondence.}

Yedy Israel, Molecular and Clinical

Pharmacology Program, Laboratory

of Genetics of Alcoholism, Institute

of Biomedical Sciences, University

of Chile, Faculty of Medicine,

Independencia 1027, Santiago RM

8380453, Chile

e-mail: yisrael@uchile.cl
Ethanol is metabolized into acetaldehyde mainly by the action of alcohol dehydrogenase in the liver, while mainly by the action of catalase in the brain. Aldehyde dehydrogenase-2 metabolizes acetaldehyde into acetate in both organs. Gene specific modifications reviewed here show that an increased liver generation of acetaldehyde (by transduction of a gene coding for a high-activity liver alcohol dehydrogenase $A D H 1 * B 2$ ) leads to increased blood acetaldehyde levels and aversion to ethanol in animals. Similarly aversive is an increased acetaldehyde level resulting from the inhibition of liver aldehyde dehydrogenase-2 (ALDH2) synthesis (by an antisense coding gene against aldh2 mRNA). The situation is diametrically different when acetaldehyde is generated in the brain. When the brain ventral tegmental area (VTA) is endowed with an increased ability to generate acetaldehyde (by transfection of liver $\mathrm{rADH}$ ) the reinforcing effects of ethanol are increased, while a highly specific inhibition of catalase synthesis (by transduction of a shRNA anti catalase mRNA) virtually abolishes the reinforcing effects of ethanol as seen by a complete abolition of ethanol intake in rats bred for generations as high ethanol drinkers. Data shows two divergent effects of increases in acetaldehyde generation: aversive in the periphery but reinforcing in the brain.

Keywords: alcohol dehydrogenase, catalase, aldehyde dehydrogenase, reinforcement, aversion

\section{INTRODUCTION: THE ETHANOL MOLECULE}

Ethanol became part of our ecology over 200 million years ago when yeast started fermenting carbohydrates in fruits and grains, generating ethanol (Ratcliff et al., 2012). Animals were subsequently exposed to ethanol in these naturally fermented products. It has been proposed (Duddley, 2000; Dominy et al., 2004) that animals that perceived ethanol as a pleasant substance had an evolutionary advantage since they also increased the intake of calories from these sources.

The pleasant effects of alcohol explain why humans engaged in manufacturing it. The book of Anni, in 1700 BC Egypt describes an overt intoxication and the rules of proper behavior to be followed in a beer shop. Subsequently, its distillation is described in $900 \mathrm{AD}$ and its production and massive consumption were brought by the Industrial Revolution (Hogarth, 1751). While in moderate doses alcohol generates motivational and reinforcing effects, in high doses it can generate aversion, inducing cognitive deficits, motor incoordination and emesis.

There is general agreement that in high concentrations ethanol modifies some neurotransmitter receptors by allosteric binding to their hydrophobic pockets, for example on the gammaamino butyric acid receptor (GABA-A) (Harris and Allan, 1985; Suzdak et al., 1986; Huidobro-Toro et al., 1987). These hydrophobic pockets are also modifiable, with similar effects, by barbiturates and anesthetics, such as enfluorane, isofluorane and other long chain aliphatic alcohols (Levitan et al., 1988;
Pritchett et al., 1989; Mihic et al., 1994, 1997; Krasowski et al., 1998).

Another receptor upon which ethanol generates hypnotic/anesthetic effects is the N-Methyl-D-Aspartate (NMDA) glutamate receptor (Lovinger et al., 1989; Weight et al., 1992). Ethanol binds allosterically to the NMDA receptor (Wright et al., 1996; Wirkner et al., 1999), an effect that leads to the interruption of cognitive processes, consolidation of memory and anesthesia (Robbins and Murphy, 2006). The hydrophobic pockets in the NMDA receptor can also be modified by anesthetics of diverse structures such as halothane, cyclopropane and xenon (Ogata et al., 2006). However, several studies indicate that the hypnotic and anesthetic effects of ethanol do not correlate with its rewarding properties (Riley et al., 1977; Daoust et al., 1987; Elmer et al., 1990).

\section{ACETALDEHYDE AS A MEDIATOR OF THE EFFECTS OF ETHANOL}

Crabbe et al. (2006) reviewed the literature on the putative role of 93 genes likely involved in the effects of ethanol. Those involved with greater frequency were alcohol dehydrogenase and aldehyde dehydrogenase. The present review deals primarily with studies that show the effects generated by increasing or reducing acetaldehyde levels and/or the ability of the liver and brain to generate it. The studies were conducted in Wistar-derived rats selectively bred for over 80 generations, which led to two lines of 
rats: the UChA (abstainer) and the UChB (bibulous). The studies to be presented dovetail with many other studies described in this issue and potentiate the concept that acetaldehyde is a major contributor of the effects of ethanol, both aversive and rewarding.

Ethanol $(\mathrm{CH} 3-\mathrm{CH} 2 \mathrm{OH})$ is a small and relatively non-reactive molecule, thus requiring high concentrations to generate its effects. In high concentrations ethanol mainly interacts with hydrophobic pockets in proteins. On the other hand, acetaldehyde $(\mathrm{CH} 3-\mathrm{CHO})$ is able to bind to amines (e.g., lysine residues) in proteins, generating Schiff bases $\left(\mathrm{CH}_{3}-\mathrm{C}=\mathrm{N}-\mathrm{CH}_{2}-\mathrm{R}\right)$, also binding to dopamine generating salsolinol, which has also been studied as a mediator of ethanol effects. Recently, Juricic et al. (2012) confirmed early studies by King et al. (1974) showing that acetaldehyde can, in addition to generating salsolinol, condense non-enzymatically with a carbon vicinal to a hydroxyl group in dopamine, yielding isosalsolinol (Figure 1). It was shown that commercial salsolinol (Sigma-Aldrich, sold prior to 2012) used in this field[,] is a mixture of four dopamine-acetaldehyde condensation products: $(R)$ - and $(S)$ - salsolinol (85\%) and (R)- and (S)- isosalsolinol (10-15\%).

\section{AVERSIVE EFFECTS OF LIVER-GENERATED ACETALDEHYDE}

Among the first studies that described powerful effects of acetaldehyde were those seen in East Asians when consuming ethanol. Studies in the 80 's demonstrated that $20-40 \%$ of individuals of East Asian origin (e.g., Japan, China, Korea) develop dysphoric effects when consuming alcohol; the effects often include peripheral vasodilatation and overt facial flushing, tachycardia, headache, nausea and emesis (Mizoi et al., 1983). Such individuals carry a point mutation in the gene that codes for the high affinity (low $\left.K_{m}\right)$ mitochondrial aldehyde dehydrogenase-2 (ALDH2*2), a mutation that greatly reduces its affinity for $\mathrm{NAD}^{+}$, thus generating a virtually inactive dehydrogenase. Subjects carrying the $A L D H 2 * 2$ polymorphism develop large increases in blood acetaldehyde (reaching $80-100 \mu \mathrm{M}$; over 5-fold that of subjects who carry the wild-type enzyme: $A L D H 2 * 1$ ). It is important to

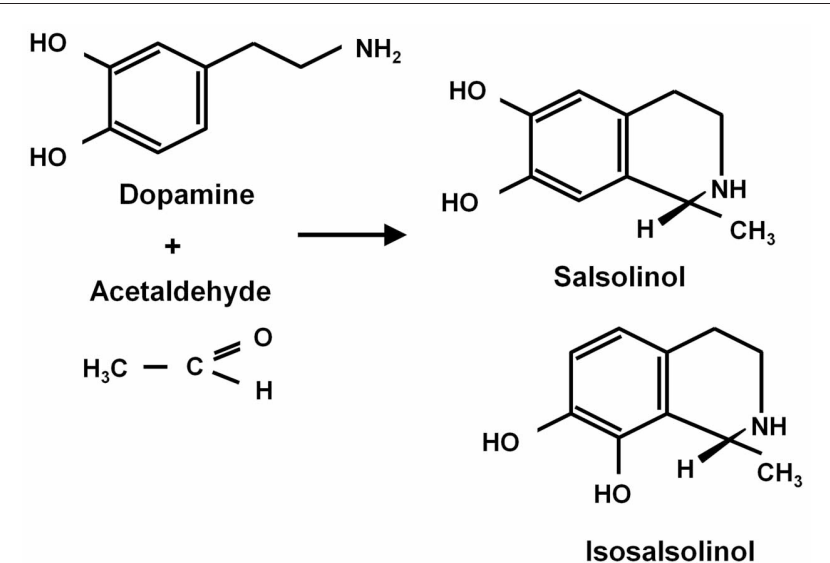

FIGURE 1 | Acetaldehyde condensation with dopamine. Products formed in the non-enzymatic condensation are (R)- and (S)-salsolinol and (R)- and (S)- isosalsolinol (from Juricic et al., 2012). note that these increases are due not only to the inability of liver to oxidize acetaldehyde into acetate, but also the inability of peripheral tissues and vascular tissues to oxidize acetaldehyde; tissues which also express the gene for high affinity mitochondrial aldehyde dehydrogenase. In venous blood of individuals carrying the normal ALDH2* 1 enzyme, the levels of acetaldehyde are virtually nil; while levels of the order of $15-20 \mu \mathrm{M}$ are found when arterial blood is sampled (see Quintanilla et al., 2007). The marked ability of endothelial tissues to metabolize acetaldehyde is of major importance in understanding why a lipophilic metabolite such as acetaldehyde does not cross the tight-junction cells that constitute the blood brain barrier (vide infra), and why the effects of acetaldehyde are so different in the periphery vs. the central nervous system.

A number of studies have shown that individuals carrying the $A L D H 2 * 2$ allele are protected between $66 \%$ (heterozygous $A L D H 2 * 1 / A L D H 2 * 2$ ) and $99 \%$ (homozygous $A L D H 2 * 2 / A L D H 2 * 2$ ) against alcoholism (Harada et al., 1982; Thomasson et al., 1991; Higuchi, 1994; Tu and Israel, 1995; Chen et al., 1999; Luczak et al., 2006; Zintzaras et al., 2006). Hence, disulfiram (Antabuse ${ }^{\circledR}$ ), a drug that non-specifically inhibits ALDH2, is the most efficient drug in the treatment of alcoholism provided its daily intake is secured by another person Chick et al. (1992), see meta-analysis by Jørgensen et al. (2011). Recent studies in animals (Escrig et al., 2012) show that disulfiram, while not showing behavioral effects on its own, reverses the anxiolytic effects of ethanol or shows anxiogenic effects. The administration of a large dose of acetaldehyde $(100 \mathrm{mg} / \mathrm{Kg})$ being anxiogenic per se.

Animal studies also support the concept that alcohol is a prodrug vis- $a$ vis their aversive effects. Rats of the UChA line (virtually Abstainer) display a mutation in the aldh2 gene (Sapag et al., 2003; see Quintanilla et al., 2006), which codes for an enzyme with a higher $K_{m}$ for $\mathrm{NAD}^{+}$and a lower Vmax that the ALDH2 of heavy drinker animals (UChB; Bibulous). Further, the levels of arterial acetaldehyde display a large "acetaldehyde burst," reaching $40-50 \mu \mathrm{M}$ (vs. 10-20 $\mu \mathrm{M}$ for controls), which deters their alcohol intake (Quintanilla et al., 2005b). The mutation in the ALDH2 gene accounts for $50-60 \%$ of the low ethanol intake of UChA rats (Quintanilla et al., 2005a).

Additional evidence that systemic acetaldehyde is aversive was seen in gene modification studies that inhibited ALDH2 activity and elevated blood acetaldehyde levels. In studies by Ocaranza et al. (2008), UChB (drinker) rats were allowed access to $10 \%$ ethanol and water for 60 days (intakes of 7-8 g ethanol $/ \mathrm{kg} /$ day), and were deprived of ethanol for 3 days. At the time of deprivation animals were injected an adenoviral vector (preferential liver tropism, but no crossing of blood-brain barrier) coding for an antisense RNA against ALDH2 mRNA, which lowered liver ALDH2 activity by $80-90 \%(p<0.001)$. When ethanol access was re-allowed, control (empty virus) animals ingested $1.2 \mathrm{~g}$ ethanol $/ \mathrm{kg} / 60 \mathrm{~min}$ (10-fold higher than a naïve $\mathrm{UChB}$ ) while animals treated with the anti ALDH2 antisense ingested $0.5-0.6 \mathrm{~g}$ ethanol $/ \mathrm{kg} / 60 \mathrm{~min}(p<0.005)$. This inhibitory effect remained constant for the 34 days of the study. Acetaldehyde levels of animals that received the antisense against ALDH2 were of the order of 60 vs. 15-20 $\mu \mathrm{M}$ in controls. 
In another study (Rivera-Meza et al., 2010), alcohol intake by $\mathrm{UChB}$ rats was reduced by $50 \%$ by the transfer into the liver (via an adenoviral vector) a rat homolog of the fast human alcohol dehydrogenase $\mathrm{ADH}_{1}{ }^{*} 2$ (ADH-47His) which elevated 6-fold liver $\mathrm{ADH}$ activity. In these studies, arterial acetaldehyde levels in the $\mathrm{ADH}_{1} \mathrm{~B}^{*} 2$ transduced animals increased from 20 to $80 \mu \mathrm{M}$ after the i.p administration of $1.0 \mathrm{~g}$ ethanol $/ \mathrm{kg}$. These studies, in addition to confirming that increases in acetaldehyde at physiological levels generate alcohol aversion in the animals, explain a large number of studies showing that humans carrying the $A D H 1 B^{*} 2$ (ADH-47His) gene are protected against alcoholism (see metaanalysis by Zintzaras et al., 2006). The lack of understanding of why this enzyme protected against alcoholism stems from the fact that acetaldehyde in humans carrying the $A D H 1 B^{*} 2$ was determined in venous blood; being close to zero. As indicated earlier, venous blood, after having perfused the rich ALDH2* 1 peripheral tissues are devoid of acetaldehyde.

From the above, genetic and pharmacokinetic evidence indicates that blood acetaldehyde in concentrations of $40-80 \mu \mathrm{M}$ is aversive to animals and to humans. The mechanism by which ethanol generates vasodilatation, hypotension and nausea could be the release of histamine from mast cells (Shimoda et al., 1996). However, antihistaminic drugs do not increase the intake of ethanol in low drinker UChA rats (Quintanilla and Tampier, unpublished). We would like to point out that it is not clear if the aversive effects of acetaldehyde are generated in the periphery beyond the liver or actually start in nerves terminals that travel from the liver to the CNS, a matter that requires study.

\section{BRAIN ACETALDEHYDE AS A MEDIATOR OF THE REWARDING EFFECTS OF ETHANOL}

Alcohol is absorbed from the stomach and intestine and is distributed throughout the body, reaching identical concentrations in the water of all tissues, including the brain. Ethanol is metabolized mainly in the liver by alcohol dehydrogenase $\left(K_{m}=2 \mathrm{mM}\right)$ generating acetaldehyde, which is further oxidized to acetate by a ubiquitous high affinity aldehyde dehydrogenase $\left(K_{m}<0.2 \mu \mathrm{M}\right)$. Other enzymes that oxidize ethanol into acetaldehyde are catalase and cytochrome p4502E1 (Figure 2). These latter enzymes play a minor role in metabolizing ethanol in the liver (Mezey, 1976; Khanna and Israel, 1980).

An important question in this field is whether liver-generated systemic acetaldehyde (normally not exceeding $20 \mu \mathrm{M}$ in arterial blood after ethanol intake) can cross the blood brain barrier. Studies indicate that since the capillaries of the blood brain barrier have tight junctions (rather than open pores) acetaldehyde must first enter the ALDH2-rich endothelial cells of the barrier, which clear the acetaldehyde. Thus, under normal conditions of ethanol metabolism, systemic acetaldehyde does not cross the blood brain barrier (Eriksson, 1977; Lindros and Hillbom, 1979; Peterson and Tabakoff, 1979; Stowell et al., 1980). Only when systemic concentrations exceed $100 \mu \mathrm{M}$, following the administration of systemic acetaldehyde, acetaldehyde enters the CNS (Tabakoff et al., 1976). High concentrations of brain acetaldehyde can also be attained by the systemic (i.p. or s.c.) administration high doses of acetaldehyde.

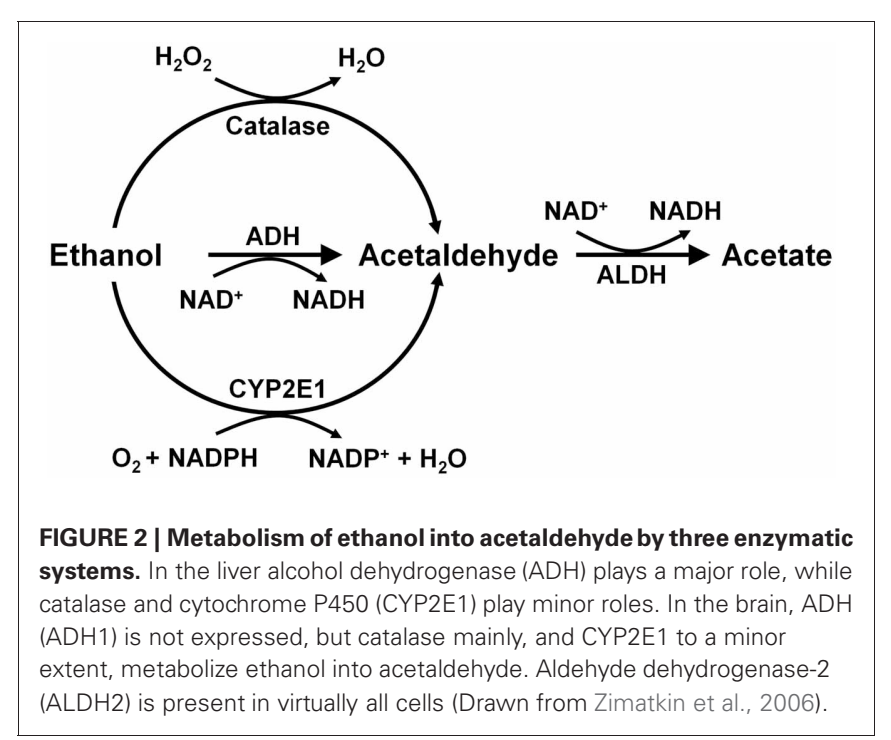

Alcohol dehydrogenase is not expressed in the brain (see Zimatkin et al., 2006; Deitrich, 2011), however, acetaldehyde can be generated from ethanol by the catalase reaction, and to a minor extent by CYP2E1, both enzymes present in brain (Tampier and Mardones, 1979; Aragon et al., 1992; Gill et al., 1992; Zimatkin et al., 2006). In vitro studies indicate that catalase generates 60 $70 \%$ of brain acetaldehyde while CYP2E1 some 20\% (Zimatkin et al., 2006). In vivo studies by Zimatkin and Buben (2007) showed that ethanol infusion into the cerebral ventricles can generate acetaldehyde (achieving $60 \mu \mathrm{M}$ ), as detected in the cerebrospinal fluid. However, the concentrations of ethanol infused (85-90 mM) were in the anesthetic range (legal limits in most countries are $6-17 \mathrm{mM})$. In these studies, the catalase inhibitor aminotriazole reduced acetaldehyde levels in the cisterna magna. While such studies were promising in pointing out a major effect of catalase in acetaldehyde generation, the low specificity of aminotriazole required caution.

The question remains as to whether enough acetaldehyde is generated following a moderate ethanol intake to induce pharmacological effects. Studies in which aminotriazole was administered showed a reduction in voluntary ethanol intake by rats (Aragon and Amit, 1992; Tampier et al., 1995). However, aminotriazole also inhibited the consumption of food and of saccharine solutions (Rotzinger et al., 1994; Tampier et al., 1995), indicating non-specific actions. With a more direct approach, Ledesma and Aragon (2013) showed that reducing brain hydrogen peroxide levels (required by catalase to oxidize ethanol to acetaldehyde) reduced alcohol-induced conditioned place preference. Most early studies in the field have been conducted by either administering large doses of acetaldehyde or by the use of inhibitors or inducers of catalase. The reader is referred to recent reviews in this field (Quertemont et al., 2005; Deitrich, 2011; Correa et al., 2012). Overall, the field generally agrees with the view that acetaldehyde mediates the reinforcing effects of ethanol; however, the methodologies used to achieve such consensus are varied, in some cases employing non-physiological concentrations and routes of administration of ethanol or acetaldehyde or non-specific inhibitors. 


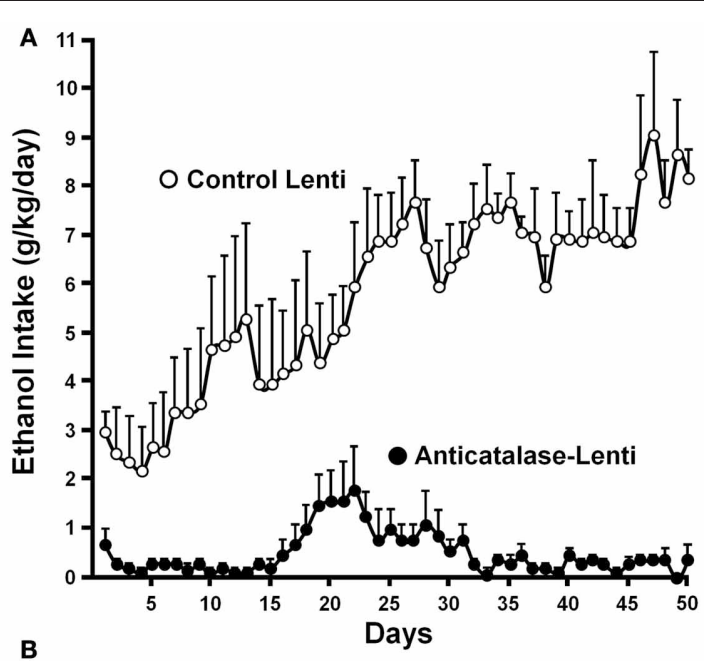

B

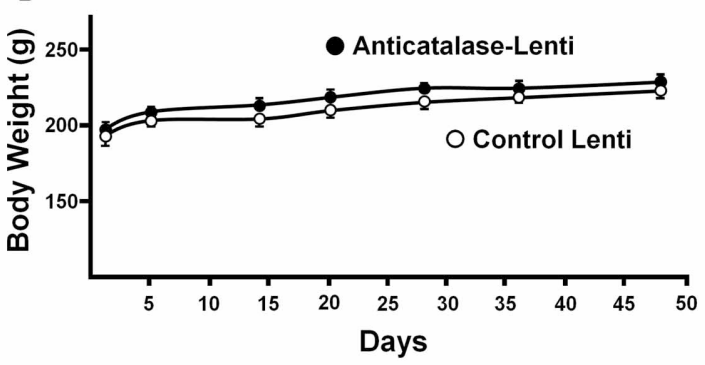

FIGURE 3 | Virtual long-lasting abolition of ethanol intake following the single administration of an anticatalase viral vector into the brain ventral tegmental area (VTA). (A) Ethanol drinker rats (UChB line) were microinjected into the VTA 1.0 microliter $\left(8 \times 10^{4}\right.$ particles $)$ of a lentiviral vector coding for an shRNA against catalase mRNA. Controls received the empty lentiviral vector. Four days after the vector injection animals had 24-h access to $10 \%$ ethanol and water. (B) Animal weight was not affected by the anticatalase vector. Water intake (not shown) was not modified either (from Karahanian et al., 2011). Replicate studies by Quintanilla et al. (2012) showed that the anticatalase lentiviral vector reduced VTA catalase activity by $70-80 \%$.

Early studies showed that rats self-administer acetaldehyde intracerebrally (Amit et al., 1977; Brown et al., 1979; Amit and Smith, 1985), indicating a reinforcing effect of this metabolite at the central nervous system level. Rodd et al. (2005) demonstrated that rats selectively bred as alcohol drinkers (strain $\mathrm{P}$ of Indianapolis) self-administer both ethanol and acetaldehyde into the brain ventral tegmental area (VTA). Acetaldehyde $(6 \times$ $10^{-6} \mathrm{M}$ ) showed reinforcing effects at concentrations that were 1000 smaller than those required for ethanol $\left(17 \times 10^{-3} \mathrm{M}\right)$ selfadministration. The question remained as to whether enough acetaldehyde is generated in the brain to develop rewarding and reinforcing effects when ethanol is consumed orally.

Recently, a specific gene blocking technique allowed inhibiting brain catalase synthesis. Karahanian et al. (2011) developed lentiviral vectors coding a shRNA designed to inhibit the synthesis of catalase. Lentiviral vectors permanently integrate into the cell genome the genes they carry. A single stereotaxic administration of an anti-catalase lentiviral vector (anticatalase-lenti) into the VTA, which reduced catalase levels by 70-80\% (Quintanilla et al.,

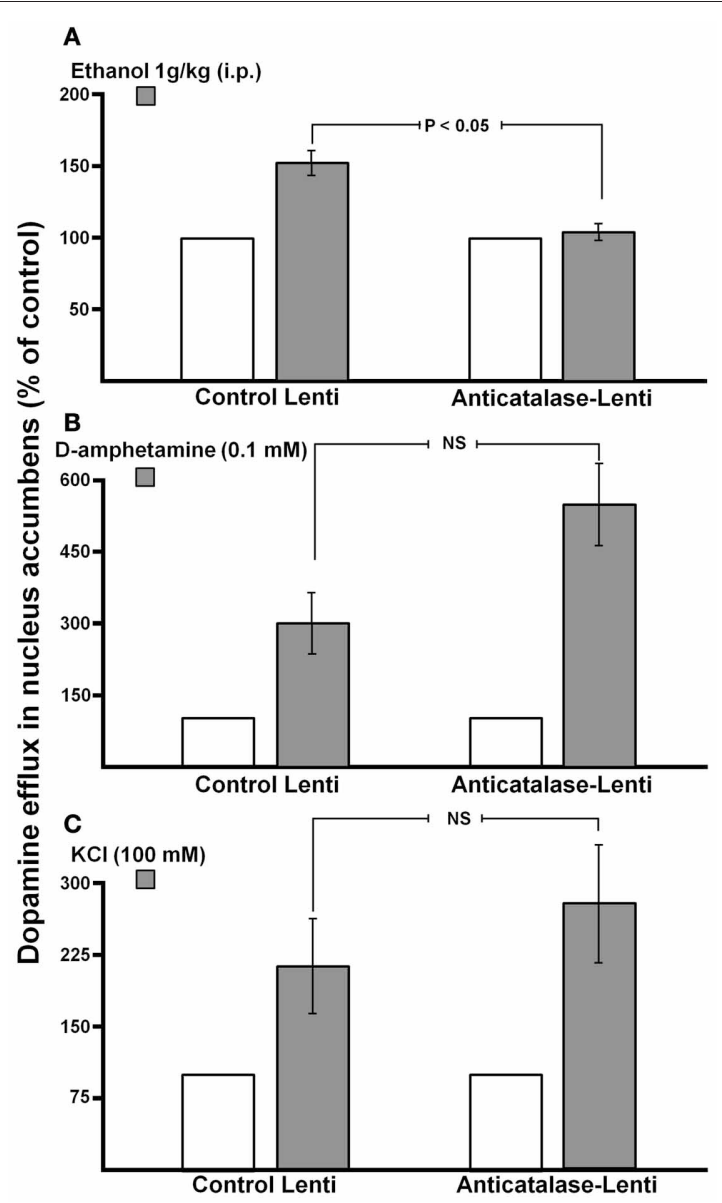

FIGURE 4 | Dopamine levels in the nucleus accumbens following acute ethanol administration. Effect of anticatalase vector administration into the ventral tegmental area on dopamine release monitored in the ipsilateral nucleus accumbens. (A) Inhibition by anticatalase-lentiviral vector of dopamine efflux into the microdialysis fluid of nucleus accumbens (shell) induced by the systemic administration of ethanol (1 g/kg i.p.). (B) Anticatalase-lentiviral vector does not affect dopamine efflux into the microdialysis fluid of nucleus accumbens (shell) induced by d-amphetamine $(0.1 \mathrm{mM})$ or (C) Anticatalase-lentiviral vector does not affect dopamine efflux into the microdialysis fluid of nucleus accumbens (shell) induced by $\mathrm{KCl}(100 \mathrm{mM})$ added to the microdialysis fluid. (From Karahanian et al., 2011).

2012), virtually abolished the voluntary ethanol consumption (up to $95 \%$ ) by drinker UChB rats for 40-50 days (Karahanian et al., Figure 3). The lentiviral anticatalase shRNA administration also abolished the increased release of dopamine in nucleus accumbens induced by ethanol administration (Figure 4). It is noteworthy that rats were not unduly affected (water intake, body weight, behavior) by the administration of the anticatalase lentiviral vector (Karahanian et al., 2011), as in the brain enzymes other than catalase are mainly responsible for the elimination of hydrogen peroxide (Halliwell, 2006), namely glutathione peroxidases and most active peroxiredoxins (Turrens, 2003; Rhee et al., 2005). Overall, the rewarding effects of ethanol appear to be mediated by acetaldehyde generated in the brain by the action of catalase. One can hypothesize that an increased ability of VTA to 


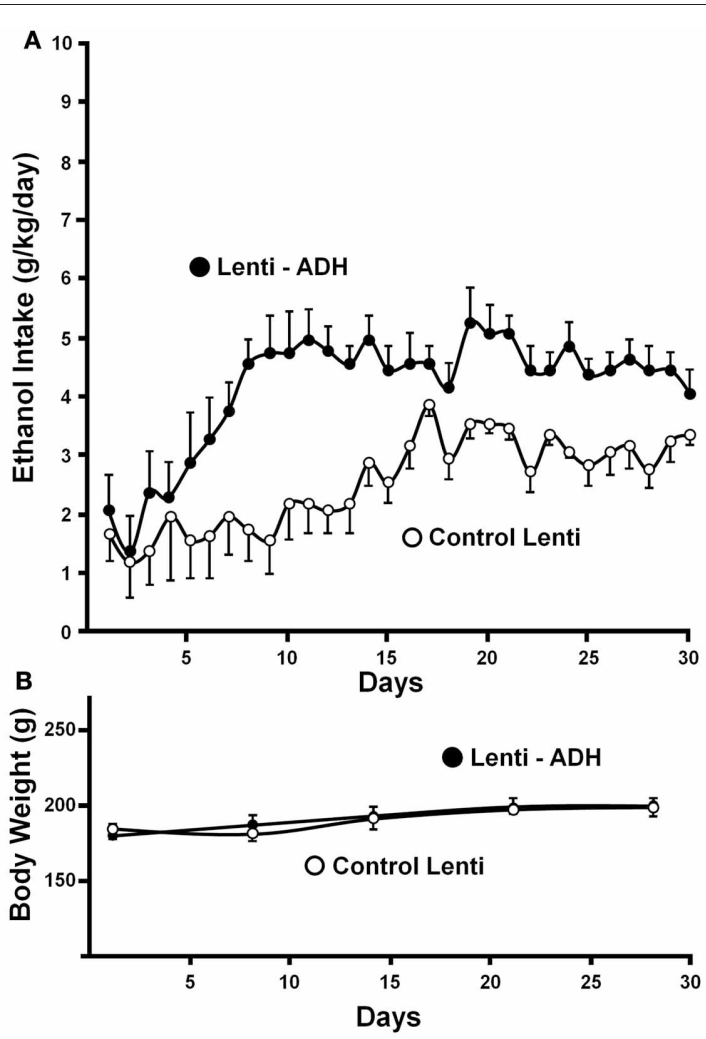

FIGURE 5 | Administration of the alcohol dehydrogenase coding gene (rat liver adh) into the VTA increases voluntary alcohol intake in rats (UChB) bred as alcohol drinkers. (A) Four days after the injection of the lentiviral vectors, animals were allowed free availability of $5 \%(\mathrm{v} / \mathrm{v})$ ethanol and water. Rats significantly $(p<0.001)$ increased their alcohol intake when injected with a lentiviral vector encoding alcohol dehydrogenase $(r A D H)$ (Lenti-ADH) into the ventral tegmental area compared to that observed after treatment with an empty lentiviral vector (control-Lenti) (A). (B) No differences in body weight were observed along the experiment in Lenti-ADH-treated rats vs. control-Lenti virus-treated rats. Abscissa: days of ethanol availability. (From Karahanian et al., 2011).

generate acetaldehyde, induced by genetic modification, should also demonstrate an increased rewarding effect of ethanol. This was tested by the administration into the VTA of a lentiviral vector coding for liver alcohol dehydrogenase. In these studies, to avoid a ceiling of the rewarding effect of acetaldehyde generated by catalase (when $10 \%$ ethanol is available to the animals, ethanol intake approaches the rate of whole body degradation), animals were allowed access to $5 \%$ ethanol and water. As can be seen in Figure 5, animals transduced with the liver alcohol dehydrogenase $(\mathrm{ADH})$ into the VTA significantly increased their ethanol intake compared to that of animals administered the control vector. The animals administered the vector coding liver $\mathrm{ADH}$ or the control vector did not show differences in body weight or behavior.

\section{BRAIN ACETALDEHYDE AS A MEDIATOR OF THE ALCOHOL DEPRIVATION EFFECT (ADE)}

Sinclair and Senter $(1968,1977)$ showed that chronic intake of ethanol by rats, followed by a period of alcohol deprivation and

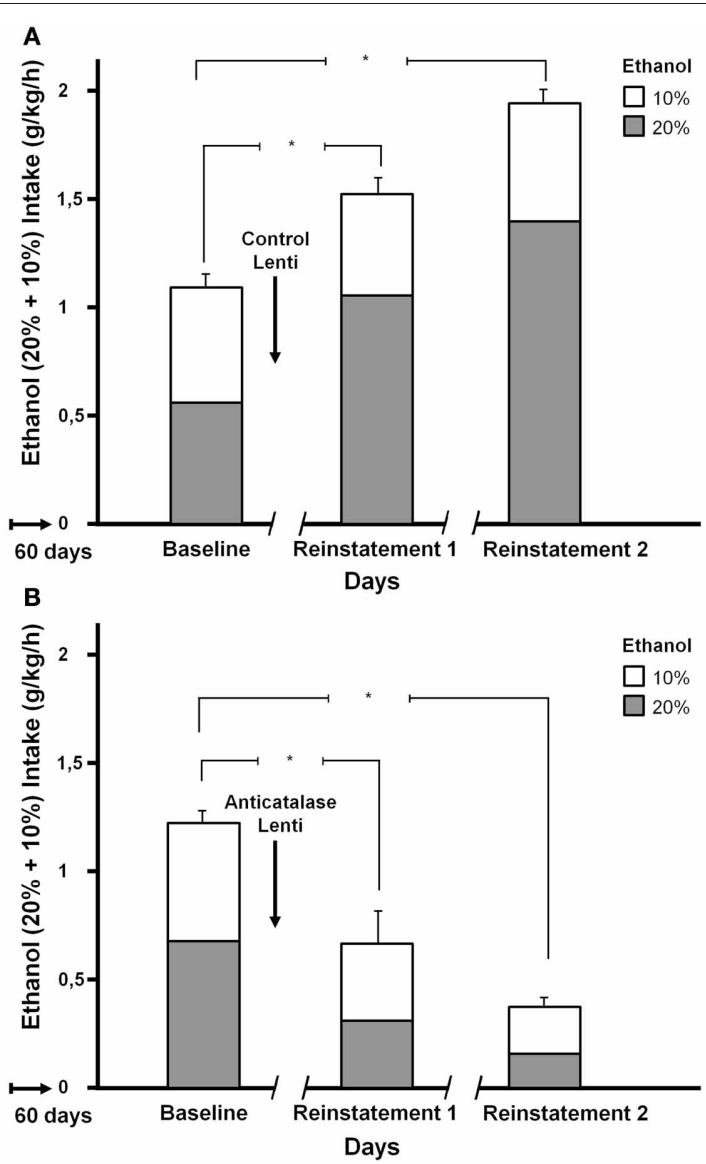

FIGURE 6 | Increased ethanol intake by UChB rats chronically exposed to ethanol, subsequently deprived and ethanol re-exposed. Marked inhibition of intake following the administration of an anticatalase lentiviral vector. Animals with ad-libitum access to 10 and $20 \%$ ethanol and water for 60 days. Baseline data correspond to the average of ethanol intake restricted to only $1 \mathrm{~h}$ a day, for 7 days immediately prior to alcohol deprivation. A single intra-ventral tegmental area injection of an anticatalase-lentiviral vector inhibited the first 1-h ethanol intake after the first and second ethanol deprivation (ADE) periods of 15 days.

The total height of each bar represents the sum of ethanol intake (g ethanol/ $/ \mathrm{kg} / 60 \mathrm{~min}$ ) of the $10 \%$ solution (empty bars) plus that of the $20 \%$ solution (gray bars). The -/ /- symbol in the $x$-axis represents the 15-day deprivation period. (A) Control viral vector. (B) Anticatalase viral vector. Arrows indicate the administration of either control lentiviral vector or anticatalase-lentiviral vector prior to the 15 days of deprivation. The first and second re-exposure consumptions were significantly different from baseline. The inhibition induced by anticatalase vector administration was $67 \%(p<0.001)$ after the first deprivation period, and $80 \%(p<0.001)$ after the second deprivation period. Note also the marked increases in ethanol binge-drinking induced in control vector treated animals after the first and second ethanol intake and deprivation cycles (From Tampier et al., 2013).

subsequent re-exposure to ethanol leads animals to a marked increase of their ethanol intake above their basal pre-deprivation levels. This effect, termed the "alcohol deprivation effect" (ADE), is shown by a marked increase in voluntary intake of ethanol solutions (akin to binge-drinking) over baseline drinking when ethanol is reinstated after the period of alcohol deprivation (Spanagel and Hölter, 1999; Rodd-Henricks et al., 2001). An ADE 
can be observed after a short (1-3 days; Sinclair and Li, 1989; Agabio et al., 2000) or a long (up to 60-75 days) deprivation period (Sinclair et al., 1973; Spanagel and Hölter, 1999), but is not observed in non-deprived continuously alcohol-treated animals, suggesting that chronic exposure to ethanol alone is not sufficient to produce such a marked increase in ethanol intake (Spanagel and Hölter, 1999). Examination of the ADE phenomenon has revealed that at least 3-4 weeks of a continuous alcohol-drinking experience are required before deprivation to elicit an ADE (Spanagel and Hölter, 1999).

A number of studies showed that repeated alcohol intakedeprivation-re-administration episodes increase the expression of ADE (see Rodd et al., 2008) and Vengeliene and colleagues (2009) have shown that the motivational and reinforcing effects of ethanol are increased in the ADE condition, as animals experiencing the ADE will increase their work to procure ethanol.

Tampier et al. (2013) asked whether in the ADE condition a greater reinforcing effect of ethanol, leading to binge drinking, is also mediated by acetaldehyde (thus, also by products generated from acetaldehyde). It was postulated that if increases in ethanol intake induced by ADE were mediated by acetaldehyde, inhibition of VTA catalase synthesis by microinjection of an anticatalase lentiviral vector should inhibit ADE binge-drinking. To test this question rats were allowed for 60 days 24 -h access to 10 and $20 \%$ ethanol solutions and water. On day 61 , rats were divided into 2 groups matched for similar 24-h alcohol consumption and preference. One group received an intracerebral administration of the control lentiviral vector and was immediately deprived for 15 consecutive days of both the 10 and $20 \%$ ethanol solution, while water was the sole fluid available. The second group was injected into the VTA the anticatalase-Lenti-shRNA. As for the viral control group, these rats were returned to their home cage and deprived for 15 days of both 10 and 20\% ethanol solutions. Following the 15 days of ethanol deprivation, re-exposure to freechoice intake of 10 and $20 \%$ ethanol and water started at 1 PM (on a normal daily cycle) and lasted for 7 days. Alcohol intake was recorded in all groups on the first hour of re-exposure (also for $24 \mathrm{~h}$ after alcohol re-exposure each day for 7 days; data not shown see Tampier et al., 2013). Thereafter, rats received a second period of 15 days of ethanol deprivation and further 7 days of ethanol

\section{REFERENCES}

Agabio, R., Carais, M. A. M., Lobina, C., Pani, M., Reai, R., Vacca, G., et al. (2000). Development of shortlasting alcohol deprivation effect in Sardinian alcohol-preferring rat. Alcohol 21, 59-62. doi: 10.1016/S0741-8329(00)00072-0

Amit, Z., Brown, Z. W., and Rockman, G. E. (1977). Possible involvement of acetaldehyde, norepinephrine and their tetrahydroisoquinoline derivatives in the regulation of ethanol seld-administration. Drug. Alcohol Depend. 2, 495-500. doi: 10.1016/0376-8716(77)90049-7

Amit, Z., and Smith, B. R. (1985). A multi-dimensional examination of the positive reinforcing properties of acetaldehyde. Alcohol 2, 367-370. doi: 10.1016/0741-8329 (85)90077-1

Aragon, C. M., and Amit, Z. (1992). The effect of 3-amino-1 2, 4triazole on voluntary ethanol consumption: evidence for brain catalase involvement in the mechanism of action. Neuropharmacology 31, 709-712. doi: 10.1016/0028-3908 (92)90150-N

Aragon, C. M., Rogan, F., and Amit, Z. (1992). Ethanol metabolism in rat brain homogenates by a catalase- $\mathrm{H} 2 \mathrm{O} 2$ system. Biochem. Pharmacol. 44, 93-98. doi: 10.1016/0006-2952(92)90042-H

Brown, Z. W., Amit, Z., and Rockman, G. E. (1979). Intraventricular

drinking; again ethanol intake on the first hour of re-intake was recorded. Figure 6 indicates that (1) UChB rats reproduced the ADE binge drinking condition showing large amounts of ethanol consumed on the first hour post ethanol deprivation (achieving an intoxicating $2 \mathrm{~g} / \mathrm{kg} / 60 \mathrm{~min}$ ) (2) subsequent deprivation ADE cycles increased ethanol intake with a greater consumption of the more concentrated ethanol solution (in line with a more reinforcing effect of ethanol after ADE), and (3) the increased in ethanol intake in the ADE condition was strongly inhibited by the anticatalase vector. After the second deprivation cycle ethanol intake was inhibited by $80 \%$. The above study strongly suggests possible therapeutic avenues in the treatment of alcoholism. It should be noted that administration of viral vectors is used in human therapies (Kaplitt et al., 2007) and are approved by agencies such as the U.S. Food and Drug Administration (FDA). Additional studies are being conducted (Karahanian et al. under review) to determine if an overexpression of rat ALDH2 in the VTA also inhibits the ADE-induced increases in ethanol intake.

\section{CONCLUSIONS}

Gene-based specific modifications show that an increased liver generation of acetaldehyde, leading to increased blood acetaldehyde levels, results in aversion to ethanol in animals. Similarly, aversion to ethanol results from an increased acetaldehyde level resulting from the inhibition of liver aldehyde dehydrogenase-2 synthesis. The situation is radically different when acetaldehyde is generated in the brain. When the brain ventral tegmental area is endowed with an increased ability to generate acetaldehyde the reinforcing effects of ethanol are increased, while a highly specific inhibition of catalase synthesis virtually abolishes the reinforcing effects of ethanol as seen by a complete abolition of ethanol intake. Data show two divergent effects of increases in acetaldehyde generation: aversive in the periphery but reinforcing in the brain.

\section{ACKNOWLEDGMENTS}

The authors' studies reported were supported by FONDECYT grants \# 1095021; \#1130012, \#1120079 and \#1110263 and the Millennium Scientific Initiative P09-015-F. Dr. Mario Rivera-Meza received a FONDECYT postdoctoral fellowship (\#3110107).

self-administration of acetaldehyde, but not ethanol, in naive laboratory rats. Psychopharmacology 64, 271-276. doi: 10.1007/ BF00427509

Chen, Y. C., Lu, R. B., Peng, G. S., Wang, M. F., Wang, H. K., Ko, H. C., et al. (1999). Alcohol metabolism and cardiovascular response in an alcoholic patient homozygous for the $\mathrm{ALDH}_{2}{ }^{\star} 2$ variant gene allele. Alcohol. Clin. Exp. Res 23, 1853-1860. doi: 10.1111/j.15300277.1999.tb04083.x

Chick, J., Gough, K., Kershaw, P., Hore, B., Mehta, B., Ritson, B., et al. (1992). Disulfiram treatment of alcoholism. Br. J. Psychiatry 161, 84-89. doi: 10.1192/bjp.161.1.84
Correa, M., Salamone, J. D., Segovia, K. N., Pardo, M., Longoni, R., Spina, L., et al. (2012). Piecing together the puzzle of acetaldehyde as a neuroactive agent. Neurosci. Biobehav. Rev, 36, 404-430. doi: 10.1016/j.neubiorev.2011.07.009

Crabbe, J. C., Phillips, T. J., Harris, R. A., Arends, M. A., and Koob, G. F. (2006). Alcohol-related genes: contributions from studies with genetically engineered mice. Addiction Biol. 11, 195-269. doi: 10.1111/j.1369-1600.2006.00038.x

Daoust, M., Lhuintre, J. P., Moore, N., Saligaut, C., Flipo, J. L., and Boismare, F. (1987). Is initial sensitivity to ethanol correlated with alcohol preference 
in alcohol-drinking and nondrinking rats. Alcohol Alcohol. 22, 409-414.

Deitrich, R. (2011). Ethanol as a Prodrug: brain metabolism of ethanolmediates its reinforcing effects - a commentary. Alcohol. Clin. Exp. Res.35, 581-583. doi: 10.1111/j.1530-0277.2011.01454.x

Dominy, N. J., Ross, C. F., and Smith, T. D. (2004). Evolution of the special senses in primates: past, present, and future. Anat. Rec. A Discov. Mol. Cell. Evol. Biol. 281, 1078-1082. doi: 10.1002/ar.a.20112

Duddley, T. (2000). Evolutionary origins of human alcoholism in primate frugivory. Q. Rev. Biol. 75, 3-15. doi: 10.1086/393255

Elmer, G. I., Meish, R. A., Goldberg, S. R., and George, F. R. (1990). Ethanol self-administration in long sleep and short sleep mice indicates reinforcement is not inversely related to neurosensitivity. J. Pharmacol. Exp. Ther. 254, 1054-1062.

Eriksson, C. J. (1977). Acetaldehyde metabolism in vivo during ethanol oxidation. Adv. Exp. Med. Biol. 85A, 319-341.

Escrig, M. A., Pardo, M., Aragon, C. M., and Correa, M. (2012). Anxiogenic and stress-inducing effects of peripherally administered acetaldehyde in mice: similarities with the disulfiramethanol reaction. Pharmacol. Biochem. Behav. 100, 404-412. doi: 10.1016/j.pbb.2011.10.002

Gill, K., Menez, J. F., Lucas, D., and Deitrich, R. A. (1992). Enzymatic production of acetaldehyde from ethanol in rat brain tissue. Alcohol. Clin. Exp. Res. 16, 910-915. doi: 10.1111/j.15300277.1992.tb01892.x

Halliwell, B. (2006). Oxidative stress and neurodegeneration: where are we now. J. Neurochem. 97, 1634-1658. doi: 10.1111/j.1471-4159.2006.03907.x

Harada, S., Agarwal, D. P., Goedde, H. W., Tagaki, S., and Ishikawa, B. (1982). Possible protective role against alcoholism for aldehyde dehydrogenase isozyme deficiency in Japan. Lancet 2, 827. doi: 10.1016/S0140-6736(82)92722-2

Harris, R. A., and Allan, A. M. (1985). Functional coupling of gammaaminobutyric acid receptors to chloride channels in brain membranes. Science 228, 1108-1110. doi: 10.1126/science. 2581319

Higuchi, S. (1994). Polymorphisms of ethanol metabolizing enzyme genes and alcoholism. Alcohol Alcohol. Suppl 2, 29-34.
Hogarth, W. (1751). "Gin lane," in Hogarth's Graphic Works, in Ronald Paulson Yale University Press, 1965.

Huidobro-Toro, J. P., Bleck, V., Allan, A. M., and Harris, R. A. (1987) Neurochemical actions of anesthetic drugs on the gamma-aminobutyric acid receptor-chloride channel complex. J. Pharmacol. Exp. Ther. 242, 963-969.

Jørgensen, C. H., Pedersen, B., and Tønnesen, H. (2011). The efficacy of disulfiram for the treatment of alcohol use disorder. Alcohol. Clin. Exp. Res. 35, 1749-1758. doi: 10.1111/j.1530-0277.2011.01523.x

Juricic, M. A., Berríos-Cárcamo, P. A., Acevedo, M. L., Israel, Y., Almodóvar, I., Cassels, B. K. (2012). Salsolinol and isosalsolinol: condensation products of acetaldehyde and dopamine. Separation of their enantiomers in the presence of a large excess of dopamine. J. Pharm. Biomed. Anal. 63, 170-174. doi: 10.1016/j.jpba.2012.02.002

Kaplitt, M. G., Feigin, A., Tang, C., Fitzsimons, H. L., Mattis, P., Lawlor, P. A., et al. (2007). Safety and tolerability of gene therapy with an adeno-associated virus (AAV) borne GAD gene for Parkinson's disease: an open label, phase I trial. Lancet 369, 2097-2105. doi: 10.1016/S0140-6736(07)60982-9

Karahanian, E., Quintanilla, M. E., Tampier, L., Rivera-Meza, M., Bustamante, D., Gonzalez-Lira, V., et al. (2011). Ethanol as a Prodrug: brain metabolism of etanol mediates its reinforcing effects. Alcohol. Clin. Exp. Res. 35, 606-612. doi: 10.1111/j.1530-0277.2011.01439.x

Khanna, J. M., and Israel, Y. (1980). Ethanol metabolism. Int. Rev. Physiol. 21, 275-315.

King, G. S., Goodwin, B. L., and Sandler, M. (1974). Isosalsolinol formation: a secondary reaction in the Pictet-Spengler condensation, J. Pharm. Pharmacol. 26, 476-478. doi: 10.1111/j.20427158.1974.tb09323.x

Krasowski, M. D., Koltchine, V. V., Rick, C. E., Ye, Q., Finn, S. E., and Harrison, N. L. (1998). Propofol and other intravenous anesthetics have sites of action on the gammaaminobutyric acid type A receptor distinct from that for isoflurane. Mol. Pharmacol. 53, 530-538.

Ledesma, J. C., and Aragon, C. M. (2013). Acquisition and reconditioning of ethanol-induced conditioned place preference in mice is blocked by the $\mathrm{H} 2 \mathrm{O} 2$ scavenger alpha lipoic acid. Psychopharmacology 226, 673-685. doi: 10.1007/s00213-012-2831-9
Levitan, E. S., Schofield, P. R., Burt, D. R., Rhee, L. M., Wisden, W. Köhler, M., et al. (1988). Structural and functional basis for GABAA receptor heterogeneity. Nature 335 76-79. doi: 10.1038/335076a0

Lindros, K. O., and Hillbom, M. E. (1979). Acetaldehyde in cerebrospinal fluid: its near-absence in ethanol-intoxicated alcoholics. Med. Biol. 57, 246-247.

Lovinger, D. M., White, G., and Wright, F. F. (1989). Ethanol inhibits NMDA-activated ion current in hippocampal neurons. Science 243, 1721-1724. doi: $10.1126 /$ science. 2467382

Luczak, S. E., Glatt, S. J., and Wall, T. L. (2006). Meta-analyses of ALDH2 and ADH1B with alcohol dependence in Asians. Psychol. Bull. 132, 607-621. doi: 10.1037/0033-2909.132.4.607

Mezey, E. (1976). Ethanol metabolism and ethanol-drug interactions. Biochem. Pharmacol. 25, 869-875. doi: 10.1016/0006-2952(76)90305-1

Mihic, S. J., McQuilkin, S. J., Eger, E. I. 2nd, Ionescu, P., and Harris, R. A. (1994). Potentiation of gammaaminobutyric acid type A receptormediated chloride currents by novel halogenated compounds correlates with their abilities to induce general anesthesia. Mol. Pharmacol. 46, 851-857.

Mihic, S. J., Ye, Q., Wick, M. J., Koltchine, V. V., Krasowski, M. D., Finn, S. E., et al. (1997). Sites of alcohol and volatile anaesthetic action on $\mathrm{GABA}(\mathrm{A})$ and glycine receptors. Nature 389, 385-389. doi: $10.1038 / 38738$

Mizoi, Y., Tatsuno, Y., Adachi, J., Kigame, M., Fukunaga, T., Hishida, S., et al. (1983). Alcohol sensitivity related to polymorphism of alcohol-metabolizing enzymes in Japanese. Pharmacol. Biochem. Behav. 18(Suppl. 1), 127-133. doi: 10.1016/0091-3057(83)90159-4

Ocaranza, P., Quintanilla, M. E., Tampier, L., Karahanian, E., Sapag, A., and Israel, Y. (2008). Gene therapy reduces ethanol intake in an animal model of alcohol dependence. Alcohol. Clin. Exp. Res. 32, 52-57. doi: 10.1111/j.1530-0277.2007.00553.x

Ogata, J., Shiraishi, M., Namba, T., Smothers, C. T., Woodward, J. J., and Harris, R. A. (2006). Effects of anesthetics on mutant $\mathrm{N}$-methylD-aspartate receptors expressed in Xenopus oocytes. J. Pharmacol. Exp. Ther. 318, 434-443. doi: 10.1124/jpet.106.101691

Oster, S. M., Toalston, J. E., Kuc, K. A., Pommer, T. J., Murphy, J. M.,
Lumeng, L., et al. (2006). Effect of multiple alcohol deprivations on operant ethanol self-administration by high-ethanol drinking replicate rat lines. Alcohol 38, 155-164. doi: 10.1016/j.alcohol.2006.06.001

Peterson, D. R., and Tabakoff, B. (1979). Characterization of brain acetaldehyde oxidizing systems in the mouse. Drug Alcohol Depend. 4, 137-144. doi: 10.1016/0376-8716(79)90054-1

Pritchett, D. B., Lüddens, H., and Seeburg, P. H. (1989). Type I and type II GABAA-benzodiazepine receptors produced in transfected cells. Science 245, 1389-1392. doi: 10.1126/science. 2551039

Quertemont, E., Tambour, S., and Tirelli, E. (2005). The role of acetaldehyde in the neurobehavioral effects of ethanol: a comprehensive review of animal studies. Prog. Neurobiol. 75, 247-274. doi: 10.1016/j.pneurobio.2005.03.003

Quintanilla, M. E., Israel, Y., Sapag, A., and Tampier, L. (2006). The UChA and UChB rat lines: metabolic and genetic differences influencing ethanol intake. Addiction Biol. 11, 310-323. doi: 10.1111/j.13691600.2006.00030.x

Quintanilla, M. E., Tampier, L., Karahanian, E., Rivera-Meza, M., Herrera-Marschitz, M., and Israel, Y. (2012). Reward and relapse: complete gene-induced dissociation in an animal model of alcohol dependence. Alcohol. Clin. Exp. Res. 36, 517-522. doi: 10.1111/j.1530-0277.2011.01606.x

Quintanilla, M. E., Tampier, L., Sapag, A., Gerdzen, Z., and Israel, Y. (2007). Sex differences, alcohol dehydrogenase, acetaldehyde burst, and aversion to ethanol in the rat: a systems perspective. Am. J. Physiol. Endocrinol. Metab. 293, E531-E537. doi: 10.1152/ajpendo.00187.2007

Quintanilla, M. E., Tampier, L., VallePrieto, A., Sapag, A., and Israel, Y. (2005a). Complex I regulates mutant mitochondrial aldehyde dehydrogenase activity and voluntary ethanol consumption in rats. FASEB J. 19, 36-42. doi: 10.1096/fj.04-2172com

Quintanilla, M. E., Tampier, L. Sapag., and Israel, Y. (2005b). Polymorphisms in the mitochondrial aldehyde dehydrogenase gene (Aldh2) determine peak blood acetaldehyde levels and voluntary ethanol consumption in rats. Pharmacogenet. Genomics 15, 427-431. doi: 10.1097/01213011200506000-00009

Ratcliff, W. C., Denison, R. F., Borrelo, M., and Travisano, M. (2012) 
Experimental evolution of multicellularity. Proc. Natl. Acad. Sci. U.S.A. 109, 1595-1600. doi: 10.1073/pnas.1115323109

Rhee, S. G., Chae, H. Z., and Kim, K. (2005). Peroxiredoxins: a historical overview and speculative preview of novel mechanisms and emerging concepts in cell signaling. Free Radic. Biol. Med. 38, 1543-1552. doi: 10.1016/ j.freeradbiomed.2005.02.026

Riley, E. P., Worsham, E. D., Lester, D., and Freed, E. X. (1977). Selective breeding of rats for differences in reactivity to alcohol. An approach to an animal model of alcoholism. II. Behavioral measures. J. Stud. Alcohol 38, 1705-1717.

Rivera-Meza, M., Quintanilla, M. E., Tampier, L., Mura, C. V., Sapag, A., and Israel, Y. (2010). Mechanism of protection against alcoholism by an alcohol dehydrogenase polymorphism: development of an animal model. FASEB J. 24, 266-274. doi: 10.1096/fj.09-132563

Robbins, T. W., and Murphy, E. R. (2006). Behavioural pharmacology: $40+$ years of progress, with a focus on glutamate receptors and cognition. Trends Pharmacol. Sci. 27, 141-148. doi: 10.1016/j.tips.2006.01.009

Rodd, Z. A., Bell, R. L., Kuc, K. A., Murphy, J. M., Lumeng, L., and McBride, W. J. (2008). Effects of concurrent access to multiple ethanol concentrations and repeated deprivations on alcohol intake of highalcohol-drinking (HAD) rats. Addiction Biol. 14, 152-164. doi: 10.1111/j.1369-1600.2008.00140.x

Rodd, Z. A., Bell, R. L., Zhang, Y., Murphy, J. M., Goldstain, A., Zafarroni, A., et al. (2005). Regional heterogeneity for the intracranial self-administration of ethanol and acetaldehyde within the ventral tegmental area of alcohol-preferring (P) rats: involvement of dopamine and serotonin. Neuropsychopharmacology 30, 330-338. doi: 10.1038/ sj.npp. 1300561

Rodd-Henricks, Z. A., Bell, R. L., Kuc, K. A., Murphy, J. M., McBride, W. J., Lumeng, L., et al. (2001). Effect of concurrent access to multiple ethanol concentrations and repeated deprivations on alcohol intake of alcohol-preferring rats. Alcohol. Clin. Exp. Res. 25, 1140-1150. doi: 10.1111/j.15300277.2001.tb02328.x

Rotzinger, S., Smith, B. R., and Amit, Z. (1994). Catalase inhibition attenuates the acquisition of ethanol and saccharin-quinine consumption in laboratory rats. Behav. Pharmacol. 5, 203-209. doi: 10.1097/00008877199404000-00012

Sapag, A., Tampier, L., Valle-Prieto, A., Quintanilla, M. E., Moncada, M. E., and Israel, Y. (2003). Mutations in mitochondrial aldehyde dehydrogenase (ALDH2) change cofactor affinity and segregate with voluntary alcohol consumption in rats. Pharmacogenetics 13, 509-515. doi: 10.1097/00008571-20030800000009

Shimoda, T., Kohno, S., Takao, A., Fujiwara, C., Matsuse, H., Sakai, H., et al. (1996). Investigation of the mechanism of alcoholinduced bronchial asthma. J. Allergy Clin. Immuno. 97, 74-84. doi: 10.1016/S0091-6749(96)70285-3

Sinclair, J. D., and Li, T.-K. (1989). Long and short alcohol deprivation effects on $\mathrm{AA}$ and $\mathrm{P}$ alcoholpreferring rats. Alcohol 6, 505-509. doi: 10.1016/0741-8329(89)90059-1

Sinclair, J. D., and Senter, R. J. (1968). Development of an alcoholdeprivation effect in rats. Q. J. Stud. Alcohol 29, 863-867.

Sinclair, J. D., and Senter, R. J. (1977). Increased preference for ethanol in rats following deprivation Psychon. Sci. 8, 11-12.

Sinclair, J. D., Walker, S., and Jordan, W. (1973). Behavioral and physiological changes associated with various durations of alcohol deprivation in rats. Q. J. Stud. Alcohol 34, 544-757.

Spanagel, R., and Hölter, S. M. (1999). Long-term alcohol selfadministration with repeated alcohol deprivation phases: an animal model of alcoholism. Alcohol Alcohol. 34, 231-243. doi: 10.1093/alcalc/34.2.231

Stowell, A., Hillbom, M., Salaspuro, M., and Lindros, K. O. (1980). Low acetaldehyde levels in blood, breath and cerebrospinal fluid of intoxicated humans as assayed by improved methods. Adv. Exp. Med. Biol. 132, 635-645.

Suzdak, P. D., Glowa, J. R., Crawley, J. N., Schwartz, R. D., Skolnick,
P., and Paul, S. M. (1986). A selective imidazobenzodiazepine antagonist of ethanol in the rat. Science 234, 1243-1247. doi: 10.1126/science. 3022383

Tabakoff, B., Anderson, R, A., and Ritzmann, R. F. (1976). Brain acetaldehyde after ethanol administration. Biochem. Pharmacol. 25, 1305-1309. doi: 10.1016/0006-2952(76)90094-0

Tampier, L., and Mardones, J. (1979). Catalase mediated oxidation of ethanol by rat brain homogenates. IRCS Med. Sci. 7, 389.

Tampier, L., Quintanilla, M. E., Karahanian, E., Rivera-Meza, M., Herrera-Marschitz, M., and Israel, Y. (2013). The alcohol deprivation effect:marked inhibition by anticatalase gene administration into the ventral tegmental area in rats Alcohol Clin. Exp. Res. doi: 10.1111/acer.12101. [Epub ahead of print].

Tampier, L., Quintanilla, M. E., and Mardones, J. (1995). Effects of aminotriazole on ethanol, water, and food intake and on brain catalase in UChA and UChB rats. Alcohol 12, 341-344. doi: 10.1016/0741-8329(95)00014-I

Thomasson, H. R., Edenberg, H. J., Crabb, D. W., Mai, X. L., Jerome, R. E., Li, T. K., et al. (1991). Alcohol and aldehyde dehydrogenase genotypes and alcoholism in Chinese men. Am. J. Hum. Genet. $48,677-681$.

Tu, G. C., and Israel, Y. (1995). Alcohol consumption by Orientals in North America is predicted largely by a single gene. Behav. Genet. 25, 59-65. doi: 10.1007/BF02197242

Turrens, J. F. (2003). Mitochondrial formation of reactive oxygen species. J. Physiol. 552, 335-344. doi: 10.1113/jphysiol.2003.049478

Vengeliene, V., Celerier, E., Chaskiel, L., Penzo, F., and Spanagel, R. (2009). Compulsive alcohol drinking in rodents. Addiction Biol. 14, 384-396. doi: 10.1111/j.1369-1600.2009.00177.x

Weight, F. F., Aguayo, L. G., White, G., Lovinger, D. M., and Peoples, R. W. (1992). GABA- and glutamate-gated ion channels as molecular sites of alcohol and anesthetic action. Adv. Biochem. Psychopharmacol. 47, 335-347.

Wirkner, K., Poelchen, W., Köles, L., Múlberg, K., Scheibler, P., Allgaier,
C., et al. (1999). Ethanol-induced inhibition of NMDA receptor channels. Neurochem. Int. 35, 153-162. doi: $\quad 10.1016 / S 0197-0186(99)$ 00057-1

Wright, J. M., Peoples, R. W., and Weight, F. F. (1996). Single-channel and whole-cell analysis of ethanol inhibition of NMDA-activated currents in cultured mouse cortical and hippocampal neurons. Brain Res. 738, 249-256. doi: 10.1016/S00068993(96)00780-9

Zimatkin, S. M., and Buben, A. L. (2007). Ethanol oxidation in the living brain. Alcohol Alcohol. 42, 529-532. doi: 10.1093/alcalc/agm059

Zimatkin, S. M., Pronko, S. P., Vasiliou, V., Gonzalez, F. J., and Deitrich, R. A. (2006).Enzymatic mechanisms of ethanol oxidation in the brain. Alcohol. Clin Exp. Res. 30, 1500-1505. doi: 10.1111/j.1530-0277.2006.00181.x

Zintzaras, E., Stefanidis, I., Santos, M., and Vidal, F. (2006). Do alcohol-metabolizing enzyme gene polymorphisms increase the risk of alcoholism and alcoholic liver disease? Hepatology 43, 352-361. doi: 10.1002/ hep. 21023

Conflict of Interest Statement: The authors declare that the research was conducted in the absence of any commercial or financial relationships that could be construed as a potential conflict of interest.

Received: 06 May 2013; accepted: 18 June 2013; published online: 08 July 2013.

Citation: Israel Y, Rivera-Meza $M$, Karahanian E, Quintanilla ME, Tampier $L$, Morales $P$ and Herrera-Marschitz M (2013) Gene specific modifications unravel ethanol and acetaldehyde actions. Front. Behav. Neurosci. 7:80. doi: 10.3389/fnbeh.2013.00080

Copyright () 2013 Israel, Rivera-Meza, Karahanian, Quintanilla, Tampier, Morales and Herrera-Marschitz. This is an open-access article distributed under the terms of the Creative Commons Attribution License, which permits use, distribution and reproduction in other forums, provided the original authors and source are credited and subject to any copyright notices concerning any third-party graphics etc. 